\title{
Tekstilde Sürdürülebilirlik: Hızlı Moda Markalarının Sürdürülebilirlik Stratejileri
}

\author{
DOI: $10.26466 /$ opus. 873787
}

\author{
Havva Halaçeli Metlioğlu * - Volkan Yakın ** \\ * Prof., Çukurova Üniversitesi,Güzel Sanatlar Fakültesi, Adana/Türkiye \\ E-Posta: hhalaceli@yahoo.com \\ ORCID: $0000-0002-8221-2589$ \\ ** Doç.Dr., Manisa Celal Bayar Üniversitesi,Akhisar MYO, Manisa/Türkiye \\ E-Posta: volkanyakin@yahoo.com \\ ORCID: $\underline{0000-0001-6518-8348}$
}

\section{Öz}

Teknolojinin gelişiminin sanayi alanında etkileri; tüketim toplumunun hızla büyümesi ve onu besleyecek hazır giyim ve moda gibi olgularn ekonomik, ekolojik ve sosyal problemlere sebep olacak kadar ağırlık kazanmasında kendini göstermiştir. Hizlanan tüketimin ve onu besleyen olgu ve mekanizmaların yarattığ artan tahribatın sürdürülemez olması, bu olguların sürdürülebilir hale getirilmesi ihtiyactn doğurmuştur. Bu ihtiyaç doğrultusunda ortaya çıkan doğal dengeyi sağlama mücadelesi, sürdürülebilirliği günümüzün en önemli üretim ve tüketim sorunlarının başına taşımışıı. Tekstil alanında sürdürülebilirlik kavramı; çevre, işgücü ve insan sağhlğı gibi konulara dikkat çekilmesini sağlamış, "yeşil tüketici", "yeşil tüketim" gibi kavramların gelişimine sebep olmuştur. Bu çalışmada, sürdürülebilirlik ile birlikte hızl moda sektöründe faaliyet gösteren HEM ve ZARA gibi markaların başarıl, sürdürülebilir tekstil üretimi ve moda stratejilerine odaklanılmıştır. Hazır giyim endüstrisi $4 R$ (reducereuse-recycle ve rebuy)prensibiyle yüksek maliyetlerine rağmen, sürdürülebilir üretim yöntemleriyle belirgin miktarda daha az tahribat yaparak üretim yapma yoluna gitmişler ve tüketicilerden olumlu geri dönüş almışlardır. Hızlı moda markalarının bu başarılarının sektörel bazda "sürdürülebilirlik" konusuna daha fazla önem verilmesini sağlayacağı düşünülmektedir.

Anahtar Kelimeler: Sürdürülebilirlik, tekstil, hızlı moda 
E-ISSN : 2528-9535

Yıl Year:11

Cilt Volume: 18

Sayı Issue :Yönetim ve Organizasyon Özel Sayısı

Temmuz July 2021

Makalenin Geliş Tarihi Received Date: 04/02/2021

Makalenin Kabul Tarihi Accepted Date: 05/04/2021

\title{
Sustainability in Textiles: Sustainability Strategies of Fast Fashion Brands
}

\begin{abstract}
The effects of the development of technology in the field of industry have manifested themselves in the rapid growth of the consumer society and the gaining weight of events such as ready-to-wear and fashion that will cause economic, ecological and social problems. The unsustainability of the increasing damage caused by the accelerated consumption and the facts and mechanisms that feed it has created the need to make these phenomena sustainable. The struggle to maintain the natural balance that emerged in line with this need has brought sustainability to the top of today's most important production and consumption problems. The concept of sustainability in the field of textile brought attention to issues such as environment, labor force and human health, and caused the development of concepts such as "green consumer" and "green consumption". This study focuses on the successful and sustainable textile production and fashion strategies of brands such as HEM and ZARA operating in the fast fashion sector with sustainability. Despite the high costs of the ready-made clothing industry with the $4 R$ (reducereuse-recycle and rebuy) principle, they have chosen to produce significantly less damage with sustainable production methods and have received positive feedback from consumers. It is thought that these successes of fast fashion brands will give more importance to "sustainability" on a sectoral basis.
\end{abstract}

Keywords: Sustainability, textile, fast fashion. 


\section{Giriş}

Sanayi devriminin ardından tekstil üretiminde hızlı bir fabrikalaşma ve seri üretim ortaya çıkmıştır. Bu süreçte geleneksel üretim yöntemlerinden uzaklaşılması yanında doğal hammaddeler ihtiyacı karşılayamayıp, gerek makine ile üretim, gerekse sentetik boyarmaddeler ve yapay liflerin kullanımı ile birlikte tekstil ve moda endüstrilerindeki seri üretimin çevre ve ekosistem üzerinde yıkıcı etkileri olmuştur. Moda olgusu tüketicilerin fiziksel ihtiyaçlarından öte, değişim arzusunu tetikleyerek psikolojik tatminleri üzerinde etkili olurken tüketim kültürünün ana mimarlarından biridir. Giyim modasında değişen silüetler, modeller, kumaşlar, desenler yeni birer kimlik paketi ve öyküsü ile tasarlanarak pazarlanmaktadır. 1980'lerden itibaren tasarım-üretim-satış döngüsünü kısaltan iş modeli ile hızlı moda tüketimi tetikleyerek sürekli satın alma arzusu yaratmıştır. Bu bağlamda hızlı moda, pazarlama ölçütleri ile tüketimi arttırırken, doğa ve ekosistem üzerinde olumsuz etkisi yanında oluşturduğu atıklarla beraber ekonomik, ekolojik ve sosyal problemler yaratmaktadır. 1970'lerden itibaren tekstil üretiminde ekolojik kaygılar ve doğaya dönüş eğilimleri etkili olmaya başlamıştır. 1990'lardan itibaren uluslararası sahnede yerini alan sürdürülebilirlik kavramı ise, çevresel, sosyal ve ekonomik bir kalkınma modeli olarak tanımlanmaktadır. Sürdürülebilirliğin temelinde gelecek nesillere aktarılabilecek biçimde kaynakların doğru ve adil biçimde kullanılması, çevreye en az zararın verilmesi, var olan insan nüfusunun tamamının insana yakışır yaşam standartlarına erişebilmesi ve yaşamını sürdürebilmesi ile yenilikçi ürünlerle ekonomiye katkı yatmaktadır. "Sürdürülebilirlik kavramı, çevrenin tüketici davranışı üzerine etkisiyle ilgili araştırmaları başlatmıştır. İlave olarak çeşitli uluslararası konferanslar tartışma ortamı yaratmışlardır. Bu tartışmalar, mevcut ve gelecek nesillerin malzeme ve diğer ihtiyaçlarını çevreye telafisi olmayan zarar vermeden ve doğal sistemlerin işleyişini bozmadan tüketim olarak tanımlanan sürdürülebilir tüketim kavramı ile tanışmayı sağlamıştır. (Bianchi, Birtwistle, 2011, s.1 ).

Bir denim pantolon için 3000 litre su ve 2 kg kimyasal kullanıldığ 1 gerçeği hızlı moda markalarını, çevre duyarlılığına sahip müşteri profilleri için sürdürülebilirlik sınavından geçmeleri konusunda çeşitli önlemler almaya itmektedir. Bu çalışmada sürdürebilirlik, moda/hızlı 
moda, yeşil pazarlama kavramları açıklanarak hızlı moda markalarından H\&M ve Zara'nın sürdürülebilirlik stratejileri ele alınacaktır.

\section{Sürdürülebilirlik, Sürdürülebilir Üretim Ve Tüketim}

Doğa üzerinde sonsuz bir hakimiyet arayışının nafile olduğunu farkeden insanoğlunun daha akılcı bir yaklaşım geliştirerek çevresel dengeyi sağlama mücadelesine girmesi sürdürülebilirlik kavramının günümüzün en önemli üretim ve tüketim sorunlarının başına taşımıştır (Clarke ve Clegg, 2000, s. 46). Sürdürülebilirlik kavramı ilk olarak, Avrupa'da 1713 yılında Alman ormancı ve bilim adamı Hans Carl von Carlowitz'in 'Sylvicultura O economica' kitabında kullanıldığı bilinmektedir (Heinberg ve Lerch,2010, s.1). Sürdürülebilirlik bugün için kalkınmayı etkileyen, hem küresel hem de yerel olarak ekolojik, ekonomik ve politik boyutları olan bir kavramdır (Joy ve ark., 2012:274, akt.Can ve Ayvaz, 2017, s.112).

Sürdürülebilirlik kavramı, ilk olarak "Club of Rome" tarafından 1972 yılında "Büyümenin Sınırları 2" adlı raporda sunulduğunda büyük ses getirmiştir çünkü rapor çok önemli bulgular ortaya koymaktaydı. Özetle rapor sonucu, Dünya gibi temelde kapalı bir sistemde nüfusun, gıda üretiminin, sanayileşmenin, doğal kaynakların sömürülmesinin ve çevre kirliliğinin er ya da geç çökmeden üstel büyümeyi sürdürmesinin imkansız olduğunu ortaya koymaktaydı. Rapor, bu felaketi önlemek için, ekonominin gelişigüzel büyümesini engellemek ve küresel dengeyi sağlamak için kolektif bir taahhüdün gerekli olacağ 1 sonucuna vurgu yapmaktaydı. (Colombo, 2001, s.7). Sürdürülebilirlilik kavramı, ilerleyen yıllarda 1987 yılında "Dünya Çevre ve Kalkınma" komisyonu tarafından gündeme getirilmiştir. Bu komisyonda sürdürülebilirlik "bugünün ihtiyaçlarını, gelecek nesillerin kendi ihtiyaçlarını karşılama kabiliyetinden ödün vermeden karşılayan kalkınma" şeklinde tanımlanmıştır (WCED,1987, s. 8). 1992 yılında ise Birleşmiş Milletler tarafından toplanan ve 178 hükümet temsilcisi, çok sayıda devlet başkanı ve 1000'den fazla STK, sivil toplum ve kampanya grubundan oluşan gerçek bir ordunun katıldığı 1992 Rio Konferansı, artık sürdürülebilirlik ve sürdürülebilir kalkınma çağının geldiğinin en büyük göstergesi olmuştur (Scoones,2007, s.591). 
İlk olarak çevresel bakış açısıyla tanımlanan sürdürülebilirlik kavramı bugün ekonomi ve sosyal açıdan da değerlendirilmektedir (Şekil1).

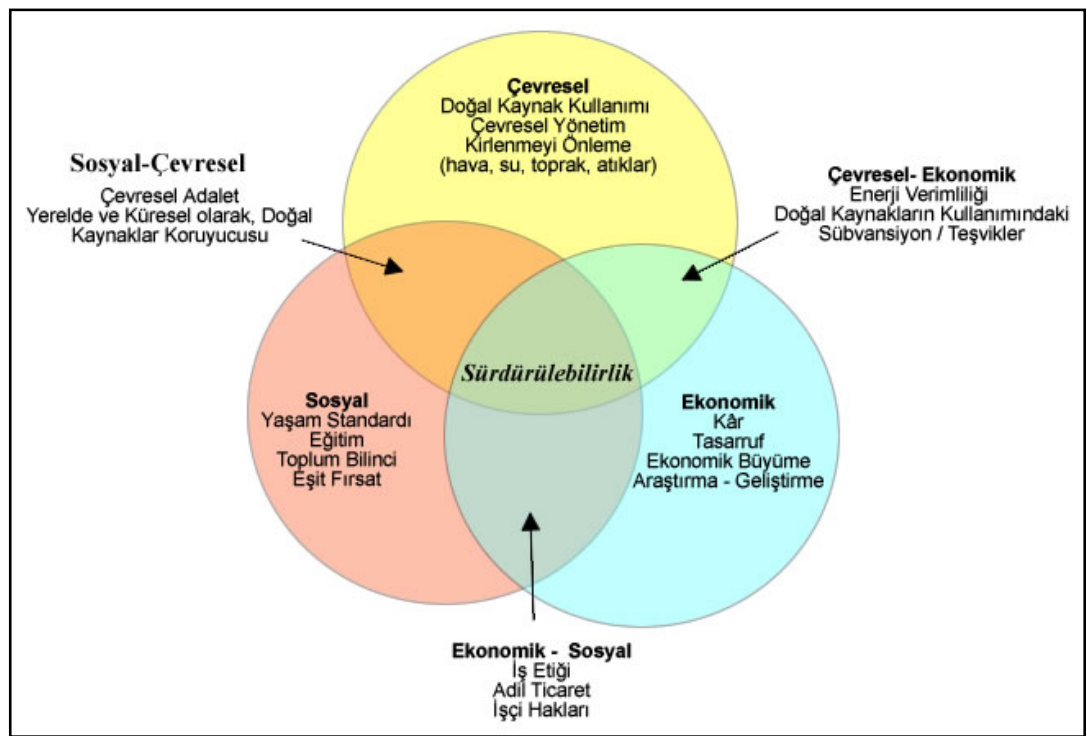

Şekil 1. Sürdürülebilirlik Ana Başlıklar ve Kapsam (Kaynak:ewa.danışmanlık.com.tr)

Sosyal bakış açısı: Zorla çalıştırmama veya çocuk işçi çalıştırmama, ayrımcılık yapmama, insanlık dışı muamele sergilememe, çalışma ortamı sağlık ve hijyen, kayıtlı istihdam, üretimde şeffaflık, ürünün sağlık ve güvenliği, bilgi gizliliği

Çevresel faktörler: Havaya atık, suya atık, toprak kirliliği, hammadde ve kaynakların kullanımı, istenmeyen etkiler (gürültü, titreşim, temizlik ve düzen).

Ekonomik bakış açısı: yerel ekonomiye katkı, yenilikçi ürünler ortaya çıkarma, kar elde etme, vergi ödeme, altyapı tesislerine yatırım, rüşvet ve yozlaşma ile mücadele.

Türkiye'de de giderek önem kazanan sürdürülebilirlik kavramı üzerine hazır giyim ve hızlı moda üreticilerinden Roteks firması bir sürdürülebilirlik raporu yayınlamıştır. Rapora göre; sürdürülebilirlik, 
üretkenlik ve çeşitliliğin devamlılığı sağlanırken, bu döngünün korunmasıdır. Bu nedenle yaşamın ve üretimin yanında, kültürel olgulara da aktarılabilecek bir kavramdır

Sürdürülebilirliğin odak noktalarından bahsedilecek olursa;

Sürdürülebilirlik kavramının yaşadığımız gezegen ve gelecek nesiller için öneminin daha geniş kitlelerce farkına varılması ürünlerin üretim süreçlerinde olduğu kadar nihai tüketici davranışlarında da önemli bir takım değişimler gözlenmesine sebep olmuştur. Sürdürülebilir üretim ve sürdürülebilir tüketim kavramları üretim ve tüketime ilişkin süreçlerin, çevresel olumsuz etkilerini devamlı olarak minimize etmeyi ve sosyal yararları maksimuma çıkarmayı hedefleyen sistem geliştirme çabaları şeklinde tanımlanabilir (Madran ve Yakın, 2017, s.75).

İşletmelerin sürdürülebilir üretim kriterleri, ağırlıklı olarak işgücüne yönelik uygulamalar (çocuk işçi çalıştırma, uzun çalışma saatleri, ayrımcılık vb.) ve çevre kirliliği (zehirli materyal kullanma, karbon salınımı vb.) gibi faktörlerden oluşmaktadır (Baskaran, Nachiappan, ve Rahman, 2012, s.647). Özellikle de son yıllarda küresel isınmanın neden olduğu iklim değişikliği gibi kaygı verici gelişmeler nedeniyle çevre kirliliğine yönelik kriterlerin önemi giderek artmaktadır.

\section{Moda ve Hizlı Moda}

Moda, sosyoloji, psikoloji, iletişim, sanat, tasarım ve ekonominin konusu olmuş ve bu alanlarla etkileşimi üzerine kuram ve görüşler ortaya konmuş bir olgudur. Türk Dil Kurumu sözlügüne göre, moda; “Değişiklik gereksinimi veya süslenme özentisiyle toplum yaşamına giren geçici yenilik, belirli bir süre etkin olan toplumsal beğeni, bir şeye karşı gösterilen aşırı düşkünlük. Geçici olarak yeniliğe ve toplumsal beğeniye uygun olan" dır şeklinde tanımlanmakta (www.tdk.gov.tr). Bu nedenle moda yeniliği, değişimi desteklemekte, teknolojik gelişmeler, bilim, sanat ve tasarımdan etkilenmekte, toplumsal değişim ve dönüşümler için de bir gösterge görevi görmektedir. Moda, kısaca tanımlamak gerekirse, belli bir zaman dilimine uygun görünüşlerdir. Bu görünüşler daha çok giyim için kullanılmaktadır. Moda, 'belirli bir zaman ve durum için tüketiciler tarafından benimsenen geçici döngüsel fenomenler' olarak tanımla- 
maktadır (Sproles,1981, s.116). Moda yalnızca giyim ürünleri değil, tüketicilerin beğenisini gerektiren diğer tüm tüketim ürünlerini de kapsayan bir kavramdır. Gardetti ve Torres $(2017$, s.6) ise modayı bireylerin diğer kişilerle iletişime geçmek ve kültürel olarak kendini ifade edebilmenin yüzeysel ve sürekli değişim eğilimi gösteren bir yöntemi olarak tanımlamaktadır.

Moda, belli bir zaman dilimini temsil etmesi nedeniyle geçici ve döngüsel bir kavramdır. Bu döngü ürünün üretilmesi, öncü kesim tarafından tanıtılması ve çoğunluk tarafından benimsenerek planlı biçimde eskiyerek görünürlüğünün azalarak sona ermesi şeklindedir (Kaiser, 1997, s.4). Moda döngüsünde, moda olan bir ürünün demode olması sürecinde yeni bir ürün piyasaya sürülüp yaygınlaşırken ekonomik bir hareketlilik de gerçekleşmekte ve moda tüketime yönlendiren yapısı ile tüketici davranışlarında önemli bir rol oynamaktadır.

1980'li yıllarda moda tedarikçilerinin kullandığ 1 bir terim olan hızlı moda, tasarımların mevcut trendleri yakalayacak biçimde defilelerden vitrinlere geçtiği bir sistemdir. Terim yalnızca defileden tüketiciye erişimin hızlı olması değil, ürünün çöpe gidiş süresinin kısalığını da belirtmektedir (www. Wikipedia.org). Hizlı moda markalarının vitrinleri 2 haftada bir değişirken, tüketici mağazaya her gidişinde yeni bir ürünle karşılaşmakta ve her yeni ürün takip edilebilecek yeni bir moda algisı oluşturarak tüketiciyi satın almaya sevk etmektedir. Her yeni ürünle, trendlere uygun tasarım ve çeşitlilik arttırılırken, ürünün raf ömrü de kısaltılarak tekrar erişiminin olmayabileceği algısı yaratılarak ürüne talep yükseltilmektedir. Ürüne erişimin kısıtlı zamanda gerçekleşecek olması, tüketiciye içgüdüsel satın alma davranışı olarak yansımaktadır. İçgüdüsel veya anlık satın alma davranışı, tüketicinin güçlü, dayanılmaz tüketme arzusuyla bir şeyi düşünmeden, kimi zaman kişinin yaşamını zora sokacak boyutlara erişebilen rasyonel olmayan satın alma deneyimidir (Verplanken ve Herabadi, 2001; Piron, 1991). Bellenger, Robertson ve Hirschman (1978) içgüdüsel satın almayı, kararının mağaza içinde verildiği alımlar olarak tanımlanmışlardır. Hızlı modanın getirdiği hızlı satın alma davranışları hızlı bir tüketimi de beraberinde getirmektedir (Tüfekçi, İ., Erciş, A., ve Türk, B. ,2014,, s.589). Iran ve Schrader, ABD'de, 1980 yılında 2.5 milyon ton tekstil atığının 1995'de 7.4 milyon ton, 2013'de ise 15.1 milyon ton olduğunu belirtmişlerdir (2017, s.1). 
Hızlı moda, farklı üreticilerle çalışan ve tasarım-üretim-satış aşamalarının ivedilikle gerçekleştiği bir döngüdür. Tüketici de bu döngünün içinde hızlı bir tüketici olarak tanımlanabilir. Hızlı moda bir moda kavramı olmasının ötesinde bir pazarlama ve iş modeli olarak da tanımlanmaktadır (Haciola ve Atilgan, 2014, s.143). Hizlı modaya tüketim ve ekonomi dışında yaklaşımlar da mevcuttur. Hızlı modanın erişilebilir fiyatları modanın her kesimden insana ulaşmasını mümkün hale getirmiş ve tüketimde demokrasi yaratmıştır. Gucci'de yıllarca çalışmış olan Tom Ford, hızlı moda konseptinin modayı demokratikleştirdiğini ve moda anlayışının değişimine yardım ettiğini belirtmiştir. Moda, yalnız üst düzey tüketici davranışı olmaktan çıktı̆̆ında uygun fiyatlarda daha geniş kitlelere ulaşabilir prensibiyle hızlı moda "bugün burada, yarın gitti" algısını kurmayı hedeflemiştir (Haciola ve Atilgan, 2014, s.144).

\section{Yeşil Pazarlama ve Yeşil Tüketici}

Çevresel sorunlar sanayi devrimi ve kentleşmenin artışıla birlikte ortaya çıkmış ve özellikle son yıllarda tüm insanlığı tehdit edecek düzeylere ulaşmıştır. İşletme ve pazarlama yönetiminin amaçlarından biri olan toplumun çıkarlarını gözetebilmek ve topluma değer katan faaliyetlerde bulunabilmek için çevresel konularda sorumluluk alan firmaların bu yaklaşımları işletme faaliyetlerinde önemli değişimler gerçekleştirmelerine neden olmuştur. Yeşil pazarlama, çevre açısından güvenli olduğu varsayılan ürünlerin geliştirilmesi ve pazarlanması anlamına gelir (www.ama.org). İşletmelerin toplumsal sorumlulukların dışında yeşil pazarlamayı benimsemelerinde rekabet ve maliyet avantajı elde etmek istemelerinin yanı sıra kimi zaman yasal düzenlemelere uymak zorunda olmaları da etkili olmaktadır.

İşletmelerin sorumlu yaklaşımın sonucunda ortaya çıkan halkla ilişkiler faaliyetleri (sosyal sorumluluk projeleri vb.) ve aynı zamanda kar amacı gütmeyen sivil toplum örgütlerinin farkındalık ve bilinçlendirmeye yönelik yürüttükleri sosyal pazarlama çalışmaları da tüketicilerin çevreci tüketim bilincini artıran davranışlar geliştirmelerine ön ayak olmuştur. 1980'li yıllarda ozon tabakasının delinmesine karşı yürütülen sosyal pazarlama çalışmaları ile ozon tabakasına zararlı gazları içeren ürünleri kullanmama davranışının gelişmesiyle ivmelenen yeşil tüketim akımı 
giderek daha yaygın hale gelmektedir. Özellikle de son yıllarda artış gösteren ve dünyanın hemen tüm coğrafyalarında gözlemlenebilen başta küresel ısınma gibi çevresel sorunlar, tüketim davranışlarında çevresel sorunların çözümünü odağına alan bilinçli tüketici sayısını önemli oranda arttırmıştır. Çevresel sorunlar konusunda bilinç düzeyi yüksek ve çevresel kaygıları tüketim davranışına yansıyan tüketiciler yeşil tüketici olarak adlandırılmaktadır. Çevresel bilinçle gerçekleştirilen satın alma eylemleri ise "yeşil satın alma" olarak tanımlanmaktadır (Handfield ve Melnyk, 1996).

Yapılan araştırmalar yeşil tüketici profilini iyi eğitim almış ve yüksek gelir grubundan kişiler olarak tanımlamaktadır (Yakın ve Dursun, 2018). Nielsen'in 2015 yılı raporuna göre de 1981-2000 yılları arasında doğan ve millenial nesli olarak tanımlanan kuşağın sürdürülebilirliğe kendinden önceki kuşaktan daha fazla önem verdiği ve yeşil ürünleri satın almak için kendinden önceki nesillere oranla daha fazla para ödemeye hazır olduklarını ortaya çıkartmıştır (Nielsen, 2015). Moisander (2007, 405) çevreci ürün ve hizmetleri: sağlığa zararlı olmayan; üretim, kullanım veya imha sırasında çevre için zarara sebep olmayan veya enerji ve diğer kaynakları orantısız miktarda tüketmeyen; hayvanların gereksiz kullanılmasına veya eziyet görmelerine neden olmayan ve çevredeki türlerin yaşamını tehdit etmeyen materyallerden türetilmiş olmayan ürünler olarak tanımlamaktadır.

Hedef kitlesi (büyük birçoğunun satın alma gücüne sahip tüketicilerin oluşturduğu) millenial kuşağı olan hızlı moda markaları için sadece ürün tanıtımı yapılması rekabet avantajı yaratmada yetersiz kalmaktadır. Aytekin ve Çelik (2017), "çevresel satın alma davranışı" ile "yeşil reklam yapan şirketlere ve ürünlerine yönelik tutumlar" arasında istatistiksel olarak anlamlı ve pozitif bir ilişki olduğunu bulgulamışlardır. Bu araştırma sonucundan, sürdürülebilirlik söz konusu olduğunda tüketicilerin ihtiyaçlarını giderirken çevreye zarar vermediklerini veya tükettikleri ürünlerin nispi oranda çevreye daha az zarar verdiğini bilmek onlar için önem taşımakta olduğu anlaşılmaktadır. Bu durum tüketimi arttıran hızlı moda markaları için ilk bakışta bir dezavantaj gibi görünmekle beraber izleyecekleri akılcı stratejiler ile durumu kendileri için avantaja dönüştürebilmeleri mümkün olmaktadır. 
Hızlı Moda Markalarının Sürdürülebilirlik Stratejileri : H\&M ve Zara Örneği

Tekstilde sürdürülebilirlik, hammadde olarak kullanılacak lifin tarım yoluyla organik bir şekilde veya sentetik olarak elde edilmesi sürecinden lifin dokuma-örme veya dokunmamış tekstil ürünü haline getirilmesi ve bu tekstil ürününün yaşam döngüsü sonunda geri dönüşüm aşamalarında kullanılan kimyasallar, enerji/su tüketimi ve tüm bu kriterlerin çevre ve insan üzerinde yarattığı etkileri de içeren bir kavramdır. Uzun yıllar konu ile ilgili sürdürülebilir ürünlerin üretimi ve tüketicinin teşvik edilerek bu tür ürünleri alması vurgulanmıştır. Hâlbuki bu ürünlerin eskilerin yerini alması yerine eskilerin muhafazasının daha etkin bir strateji olduğu açıktır. Daha da önemlisi bir ürünün yaşam döngüsünde çevreye verdiği zararın \% 601 ürünün kullanımı sırasında olduğu görülmüştür (Iran ve Schrader, 2017). Hizlı moda akımı yüzünden 2000-2015 yılları arasında dünya nüfusu 5 de 1 oranında artarken giysi üretimi 2 katına çıkmış ve ucuzlukları nedeniyle bu giysiler 3 de 1 oranında daha az giyilerek atık haline gelmiş, dünyanın aynı yıl içinde çöpe attığı giysilerin değeri 450 milyar doları aşmıştır (Kunzing, 2020, s.60).

Tekstil ürünlerinin çevreye verdikleri zarar konusunda örnekler çoğaltılacak olursa;

- Mikroliflerden üretilmiş tekstil ürünlerinin kullanımı sonucu 50 milyar plastik şişeye denk 500000 ton mikrolif okyanuslara karışmaktadır.

- $\quad \mathrm{ABD}^{\prime}$ den yılda 12 milyon ton, $\mathrm{AB}^{\prime}$ den 6 milyon ton tekstil açı̆̆ çıkmaktadır (Saka, 2018)

- $\quad$ "Her yıl hazır giyim endüstrisi 2 milyon ton atık ve 2.1 milyon ton karbon dioksit ve 70 milyon ton su harcamaktadır" (Mangır, 2016, s.50).

$\mathrm{Bu}$ nedenle günümüzde tekstil atıklar için de atıkların kullanımı ve çevreye en az zarar verecek biçimde dönüşümü için çeşitli önlemler alınmakta ve sürdürülebilirlik doğrultusunda prensipler benimsenmektedir. Kisaca 3R olarak tanımlanan reduce-reuse-recycle (azalt-geri kullangeri dönüştür) prensibine son yıllarda yeniden satın alma (rebuy) boyutunun eklenmesi ile 4R konsepti oluşmuştur. Birçok firma duyarlı müşteri kitlesini hedefleyen ürünleri bu doğrultuda mağazalarında 
müşterilerine sunmaktadır. $\mathrm{Bu}$ firmaların başında hızlı modanın öncülerinden olan H\&M gelmektedir ve koleksiyonlarının bazı parçalarında toplanan giysilerden dönüştürülmüş malzemeler kullanarak üretmektedir. H\&M 2013 yılından beri mağazalarında müşterilerinden kullanılmış giysileri verdiği indirim çekleriyle geri alarak dünya ekonomisine katkı sağlamaktadır (Atalayman, 2019, s.35 ).

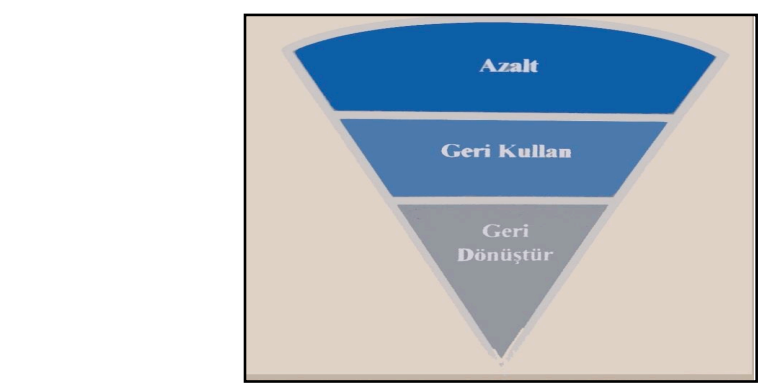

Şekil 2: Atık azaltma hiyerarşisi (Kaynak: Steiner, Wiegel, 2009, s.18)

Hızlı moda markalarının sürdürülebilirlik stratejilerinin anlaşılması için geri dönüşüm, düşük ve yüksek döngü kavramlarının açıklanması da gereklidir. William McDonough ve Michael Braungart 2002 yılında yayınladıkları Cradle to Cradle: Remaking the Way We Make Things (Beşikten beşiğe: yeniden yapım) adlı eserlerinde geri dönüşümde yüksek ve düşük döngü ayrımı yapmışlardır. Yüksek döngü, kullanılmış faydalı malzemelerin boşa harcanmasının önlenmesi ve mevcut malzemelerle üretim yapılması olarak tanımlanmıştır. Böylece yeni malzeme kullanımına gerek duyulmayarak israf önlenirken, enerji kullanımı, kirlilik ve gaz emisyonu azaltılmaktadır (Şanlı, 2018, s.12).

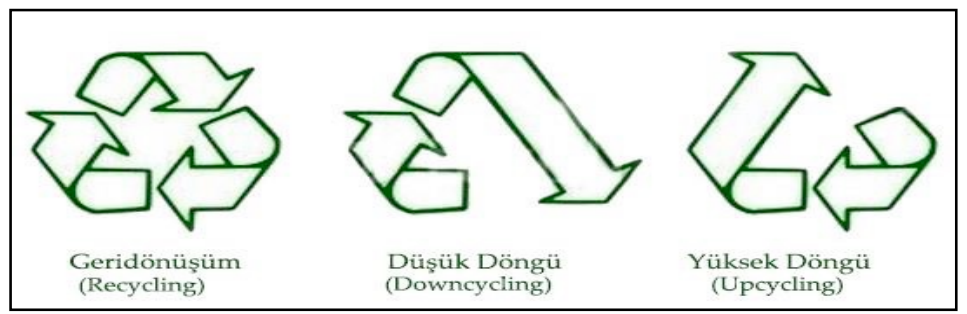

Şekil 3: Geri Dönüşü̈m, Dïşük Döngü ve Yüksek Döngü Şeması (Kaynak: Yanmaz, 2014, s.19) 
Moda kavramı yukarıda da tanımlandığı üzere sürekli değişimi ifade etmektedir. Ürünlerin kısa süreli kullanımları nedeniyle moda ve özellikle de hızlı moda kavramının sürdürülebilirlik ile birlikte ele alınması çelişkili görünmekle birlikte konuya doğru bir şekilde yaklaşılırsa ve sürdürülebilirlik hedeflerine karşı duyarlı ve anlayışlı olunursa, tasarım modası, evrimsel süreçte ekolojik ve sosyal açıdan sorumlu bir şekilde materyaller üretme yolunda değerli bir müttefik olabilecektir (Walker, 2006, s.72). Etik tüketim, giyim pazarında etik moda kavramını doğurmuştur. Joergens' in 2006 'da tanımladığı üzere etik moda, "çalışanların adil ticaret prensiplerine uygun bir ortamda çalıştığı ve çalışan sağlığına veya çevreye zarar vermeyecek şekilde doğada çözülebilir ve organik pamuğun kullanıldığı modaya uygun giysilerdir (Wigley ve ark., 2012, s.938,)

Son yıllarda hizlı moda markaları da bu kavrama önem vermeye başlamış ve bu yönde stratejiler geliştirerek marka algılarını çevreci bir konuma getirme çabasına girmişlerdir. Büyük ölçekli tedarikçiler, Zara ve $H \& M$ bu duruma cevaben sürdürülebilir hamlelerde bulunmaktadır ve bu eğilim giderek büyümektedir. Bunun yanında, küresel ekonomi ve paylaşım ekonomisi gibi sosyoekonomik ve makro trendler geleneksel seri tüketim paradigmalarıyla mücadele ederken sürdürülebilirliği sonradan akla gelen bir düşünce değil bir tasarım elemanı olarak gören yeni ve yenilikçi iş modellerini öne sürmektedir (Todeschini, Cortimiglia, Callegaro-de-Menezes, Ghezzi , 2017, s.760).

H\&M, sürdürülebilirlik kapsamında önemli adımlar atmaktadır. İnternet sayfasında belirlediği 3 strateji kısaca "insanlara ve çevremizdeki topluluklara "adil ve eşit olma", dünyanın kaynaklarını sorumlu biçimde kullanarak "döngüsel\&iklim" dostu firma olma ve moda endüstrisinin itici gücü olup yeniden icat ve dönüşüm konusunda "değişim lideri" olma (H\&M Group Sustainability Report, 2017). Bu açıdan bakıldığında H\&M modaya yeni bir soluk ve tanım getirmek için sürdürülebilir moda anlayışı oluşturmak üzere inovatif çözümler üretme konusunda küresel varlığını ve ölçeğini kullanarak endüstrinin dönüşümü için katalizör görevi üstlenmektedir. Bu amaçla inovasyon ödülleri verirken, geleceğin modasını şekillendiriyoruz diyerek bilim insanları ile işbirliğini manifestosuna eklemiştir.

Science Story, H\&M ile yaratıcı düşünürler, araştırmacılar ve tekstil endüstrisinin çevresel etkileriyle mücadele etmek için tasarlanmış son 
teknoloji materyaller geliştiren bilim insanları arasındaki bir iş birliği sonucu üretilmiş bir koleksiyondur. Koleksiyon, yetişmesi için çok az su gerektiren, kaktüs bitkisinden elde edilmiş vegan deri olan Desserto ${ }^{\circledR}$ içermektedir.(https://www2.hm.com/tr tr/hm-sustainability/letschange.html/archive/science-story).

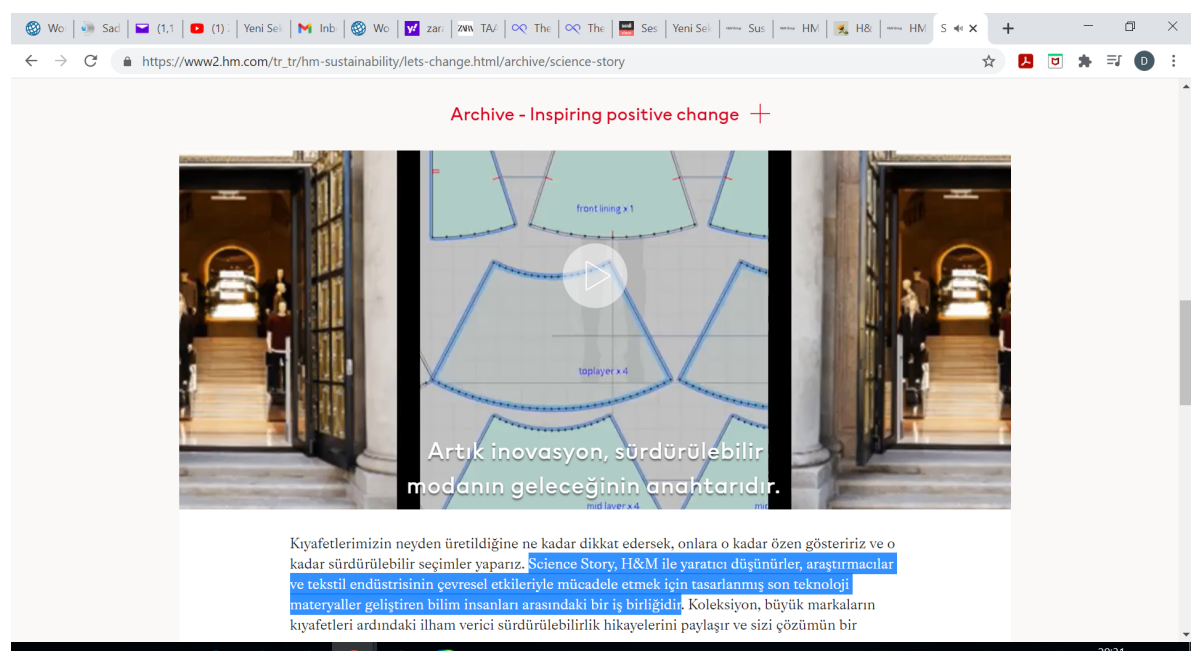

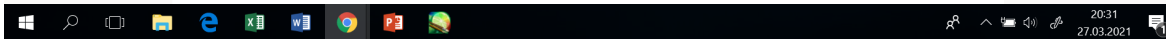

Şekil 4. Inovasyon sürdürülebilir modanın anahtarıdır tanıtım filmi Kaynak: (https://www2.hm.com/tr).

H\&M, sürdürülebilir hammaddeler üzerine yapılan araştırmaları desteklerken, vegan üzüm derisi Vegea ${ }^{\mathrm{TM}}$, narenciye kabuklarından elde edilen ipek benzeri Orange Fiber ve mahsul atıklarından elde edilen doğal bir lif olan Agraloop ${ }^{\mathrm{TM}}$ BioFibre ${ }^{\mathrm{TM}}$ gibi lifleri koleksiyonlarına eklemiştir.

Sürdürülebilirlik stratejileri arasında adalet ve eşitlik ilkesini de benimseyen H\&M, adil ücretler ve iyi çalışma koşullarını garanti etmekte, cinsiyet eşitliğini desteklemektedir. Fashion Revolution tarafından yürütülen dünyanın en büyük 250 markasının ve perakendecisinin belirli sosyal ve çevresel sürdürülebilirlik konularında ne kadar şeffaf olduğunun değerlendirildiği Moda Şeffaflığ Endeksinde 2020'de en yüksek puanı alan marka olmuştur (https://www2.hm.com/tr).

2018 yılı sürdürülebilirlik raporuna göre H\&M, 2020 yılına kadar tüm ürünlerinde $\% 20$, 2030 yılına kadar ise $\% 100$ ünde sürdürülebilir veya geri 
dönüştürülmüş lif kullanımını hedeflemektedir. Bunun yanında bilinçlisürdürülebilirlik (conscious sustainability) koleksiyonundaki her ürünün üretildiği ülke ve fabrika koşullarını tüketicinin erişebileceği biçimde web sayfasında yayınlamakta ve aynı bilgiler ürün etiketinden elde edilebilmektedir. Yanı sıra 2018 yılında 20649 ton tekstil yeniden kullanım ve geri dönüşüm için H\&M mağazalarında toplanmıştır. Bu rakam önceki yıla nazaran \%16 artış göstermiş ve 103 milyon tişörte denk gelmektedir. 2019 yılında ise toplanan ürün miktarı, 145 milyon tişörte denk gelen 29005 tona yükselmiştir.

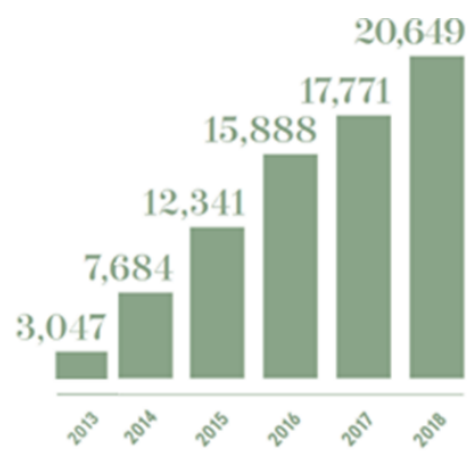

Şekil 5. HEM mă̆azalarında toplanan ürünlerin miktarlarının yıllara göre dağılım grafiği (Kaynak: HEM Group Sustainability Report 2017)

H\&M, 2017 yılı bahar sezonunda "bring it on" kampanyası ile eskiyen, solan, yırtılan tekstil ürünlerini mağazalarında toplamak için daha fazla vicdan azabı çekmeyelim başlığı ile düşük ve yüksek döngüde geri dönüşümü hedeflemiştir. Toplanan giysilerden bazıları 2. el giysi olarak kullanılırken, diğerleri metallerinden ayrılıp, sökülüp, kesilip temizlik bezi veya dolgu maddesine dönüştürülmekte, lif haline getirilenler ise yeniden dokunup Jean koleksiyonunda döngüye katılmaktadır. Oluşan artıklar toz haline getirilip karton yapımında kullanılmaktadır. H\&M bu işlemleri kapalı döngü olarak tanımlamaktadır (H\&M Conscious: Bring it on https://www.youtube.com/watch?v=7i4JSzB8VlU) 


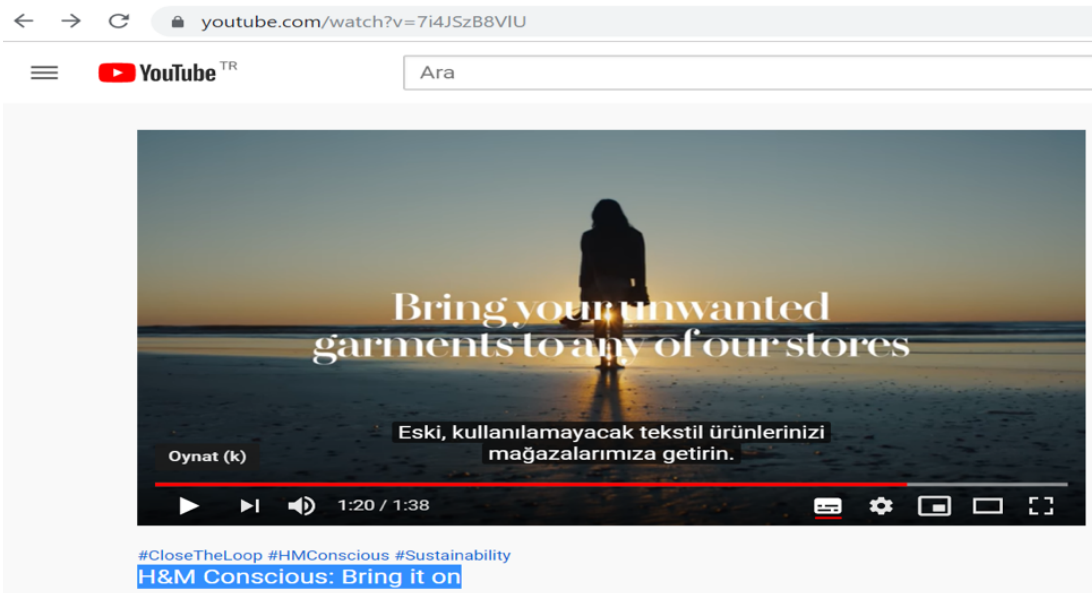

Şekil 6. HEM youtube reklamı (Kaynak: www.youtube.com)

5 Ekim 2017'de H\&M mağazalarından toplanan giysilerden elde edilmiş sürdürülebilir ve geri dönüştürülmüş pamuktan kapalı döngü denim koleksiyonunu tanıtmıştır. Sokak modasında ve sosyal medyadaki vintage denimin dönüşünden ilham alan koleksiyon 6 parçadan oluşmuş ve H\&M mağazalarında satışa sunulmuştur (http:// makeitlast.se).

H\&M sürdürülebilirlik anlayışında tasarım ve üretime devam ederken 2019 yılında 'Conscious' koleksiyonunu tanıtmıştır. Sonbahar koleksiyonundaki her parçanın en az \% 50 si pet şişelerden yüksek döngüde elde edilmiş polyester içermektedir. Bu koleksiyona ait reklam filmi dijital platformlar da dahil olmak üzere çeşitli medya ortamlarında yayınlanmaktadır (Anderson, 2019).

H\&M, tekstilde sürdürülebilirlik için en iyi çözümün belli bir ürünün muhafaza edilerek ömrünün uzatılması prensibiyle hareket ederek "az yıkayın, onarın, geri dönüştürün ve tekrarlayın" sloganını belirlemiştir. Bu amaçla, Stockholm, Viyana, Londra ve Paris'teki büyük mağazalarında kıyafetlere onarım ve yenileme yaptırılabilecek onarım atölyeleri kurmuştur.

H\&M sıfır atık prensibinde döngüsel moda insiyatifi Ellen McArthur Vakfı ile işbirliği içinde olup, tasarım, malzeme, üretim süreci-kullanmabakım-onarım, yeniden kullanım, geri dönüşüm, tasarım döngüsü yaklaşımıyla hareket etmektedir. Bu amaçla ürün ömrünün uzatılması ve atık 
miktarının azaltılmasını sağlayacak çözümler üzerine çalışılmaktadır. H\&M'in sürüdürlebilirlik mmonusundaki son girişimi ise giysi kiralama sistemi olmuştur. Stokholm'deki bir mağazasında "Conscious" koleksiyonundan parçaların kiralanmasına imkan veren bir system denenmektedir ( HM-Group-sustainability-performance-Report-2019).

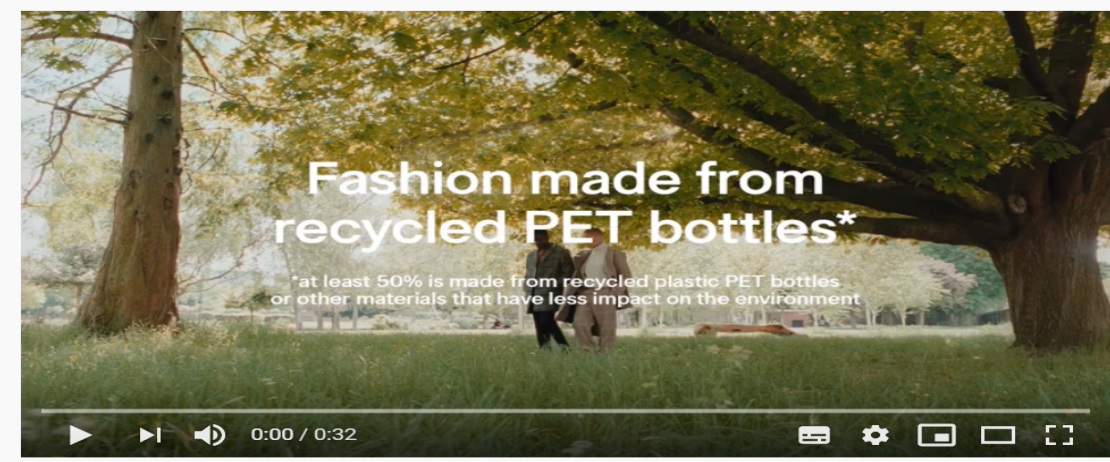

Şekil 7. HEM youtube reklamı (Kaynak: wwww.youtube.com)

Zara ise sürdürülebilirlik stratejileri açısından sosyal, ekonomik ve çevresel ayakları bulunan adımlar atmıştır. Bu doğrultuda Zara kamuoyuna 2025 yılına kadar tüm ürünlerinin sürdürülebilir olacağı taahhüdünde bulunmuş, mağazalarında eski ürünlerin toplanacağı konteynırlara (taşımalık) yer verileceğini belirtmiştir. Zara'nın bağlı olduğu Inditex grubu, 2020'ye kadar sahibi olduğu tüm markalarda plastik poşet kullanımına, 2023 yılına kadar da tek kullanımlık poşetlere son vereceklerini duyurmuş, yanı sıra kıyafetlerinde organik pamuk ve geri dönüştürülebilen polyester kullanımını teşvik etmektedir (bbc.com).

Zara internet sitesinde, Sustainable Apparel Coalition tarafından geliştirilen Higg endeksini temel alan "join life" standardını benimsediğini ve bu standardı ürün üretim süreçlerine de dahil etmek için tüm tedarikçileri ile de işbirliği içinde olduğunu belirtmektedir (https://www.zara.com/tr/tr/surdurulebilirlik-urunler-mkt1455.html).

Higg endeksi, bir marka, ürün veya kuruluşun sürdürülebilirlik yolculuğunun her aşamasında şirket veya ürünün sürdürülebilirlik performansını ölçen araçlardır (The Higg Index). 


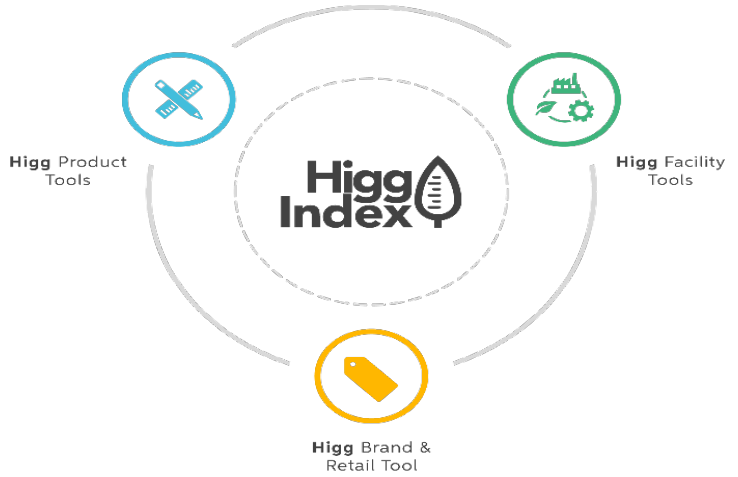

Şekil 8. Marka-tedarik, Ürün ve Tesis araçlarından oluşan Higg endeksi (Kaynak: https://apparelcoalition.org/the-higg-index/)

Zara 2019 yılından itibaren giyim koleksiyonunda sürdürülebilir ürünleri için "join life" etiketi kullanırken, +care for fiber, +care for water ve +care for planet başlıkları altında sürdürülebilir stratejilerine web sitesinde yer vermiştir. +Care for fiber, geri dönüştürülmüş polyester iplikler geri dönüştürülmüş yün ve pamuk, TENCEL $®$ lyocell veya tamamı organik pamuk gibi sürdürülebilir ana maddelerden üretimi tanımlamaktadır. Geri dönüştürülmüş yün ve pamuğun kullanımı, gerek pamuk üretimi; gerekse yünün iplik haline getirilmesinde harcanan su ve enerjiyi azaltmakta ve doğal kaynak tüketimini minimize etmektedir. Geri dönüştürülmüş polyester ise, atık pet şişelerden elde edilen petin iplik haline getrilmesiyle işlenmemiş hammadde üretimini, su ve enerji tüketimi ile azaltarak daha az atık üretilmesini sağlamaktadır.

Zara, aynı zamanda benimsediği döngüsellik prensibi ile üretim sürecinde oluşan kesilmiş kumaş atıklarının yeni kıyafetlerde kullanılmasına izin veren bir sistem üzerinde çalışmaktadır. Join life lyocell ürünlerin üretim artıklarını kullanarak mekanik yöntemlerle geri dönüştürülmüş bir lif olan geri dönüştürülmüş lyocelli tasarlamıştır ve bunu geri kazanım lyocelll ipliğe dönüştürmüştür. Zara geri dönüştürülmüş kuştüyü ve geri dönüştürülmüş deriye de ürün gruplarında yer vermektedir.

+Care for water, üretim sürecinde su tüketiminin azaltıldığı kıyafetler olup, kıyafetlerin boyama veya yıkama süreçleri suyun en çok tüketildiği 
aşamalardır. Ozon veya cold pad boyama gibi teknolojiler veya suyun yeniden kullanımına izin veren kapalı döngülerin kullanımı su tüketiminin azaltılmasına yardım etmektedir.

+Care for planet başlığında ise emisyonları ve/veya üründe kimyasal kullanıminı azaltmaya izin veren yenilenebilir enerji gibi teknolojilerin kullanımı ile üretilen giysiler olarak açılanmıştır. Zara 2025 yılında $\% 100$ daha sürdürülebilir pamuk, keten ve $\% 100$ geri dönüştürülmüş polyester kullanımı ile, \%80 yenilenebilir enerji tüketimi ve Ellen McArthur Vakfı tarafından yeni plastik ekonomisi taahhütlerinde bulunmuştur. Zara yalnız giysi üretim zincirinde değil, aynı zamanda, ürünlerin paketlenmesinde ve mağaza mobilyalarında biyoçeşitliliğin korunmasını destekleyen hammadde kullanımını teşvik etmektedir (https://www.zara.com.).

Tüm bu yönleri ile incelendiğinde H\&M ve Zara'nın hızlı moda marka imajından sürdürülebilir markalar imajları yaratmakta olduğu ve yeşil pazarlama ile yelşil tüketicileri hedeflediği söylenebilecektir.

\section{Sonuç}

Gelişen toplumda nüfus arttıkça bireysellik ihtiyacını; toplumsal statü ve kendini ifade gibi olgularla ortaya koymak isteyen tüketiciler teknolojik gelişmeler çerçevesinde post modern tüketim davranışları sergilemeye başlamışlardır. Bu durum çoğu tüketici için tüketimin sadece fiziksel ihtiyaçlar için değil aynı zamanda kendi kimliğini yansıtmanın bir yolu olarak psikolojik birtakım ihtiyaçların da giderilmesi amacıyla gerçekleşmesi ve üreticilerin ürün ve hizmet satabilmeleri için yeni fırsatlar yaratabilmeleri anlamına gelmektedir. Diğer taraftan üretim sürecinin kıt kaynaklar ile gerçekleştiriliyor olması nedeniyle bu durum yönetimsel açıdan bir paradoks yaratmaktadır. Sürdürülebilirlik kavramı, insanın artan refah talebini karşılamada kullandığı üretim ve tüketim mekanizmalarının sebep olduğu refah azalmasını dengeleme ihtiyacından doğmuştur. 1980'lerden itibaren "hızlı moda" kavramını tüketiciyle tanıştıran tekstil sektörü, moda olgusuna paralel olarak sürekli yeni ve farklı ürünler talep eden tüketicilerin isteklerine yanıt vermeye çalışarak üretim-tüketim döngüsünü kısaltmıştır. Üreticilerin ve tüketicilerin kesiştikleri bu arz ve talep noktası hızlı moda sektörünün tüm dünyada kabul gören bir akıma dönüşmesine neden olmuştur. 
Sonuç olarak diğer birçok tüketim ürünleri sektöründe olduğu gibi tekstil sektöründe de üretim artmaya devam etmiştir. Bu durum, sürdürülebilirlik açısından sorumsuz bir üretimin çevresel, sosyal ve ekonomik boyutlarıyla toplum ve insan sağlı̆ 1 konularında yarattığ tahribatın görünür hale gelmesine ve toplumsal refahın azalmasına neden olmuştur. Bu nedenle üretim ve tüketimin dengelenmesiyle birlikte, sosyal ve ekonomik refah artışının sürdürülebilmesi hem üreticiler hem de bilinçli tüketiciler açısından her geçen gün giderek önem kazanan bir konu olmuştur. Bu amaçla ortaya konan sürdürülebilirlik kavramının moda üzerindeki etkileri, toplumsal ve çevresel bilinç düzeyinin ve sosyal medyayı aktif kullanarak sesini duyurma imkanına kavuşan bilinçli tüketicilerin artmasıyla "yeşil moda" ve "yeşil üretim/tüketim" kavramlarının doğuşunda kendini göstermiştir. H\&M ve Zara hızlı tüketimle beraber yarattıkları çevreye zarar veren imajlarını sürdürülebilirlik kavramı, yeşil moda kavramı ve $4 \mathrm{R}$ ((azalt-geri kullan, geri dönüştür, geri satın al) konseptini uygulayarak sürdürülebilir markalar statüsüne taşımaya çalışmaktadırlar. Bu amaçla üretimde sürdürülebilir hammadde ve yenilenebilir enerji kullanımı ve daha az su tüketimi ile tekstil ve modada kullanılan Higg sürdürülebilirlik endekslerini taahhüt ederken, yeşil tüketicileri de hedef kitlelerine eklemektedirler. H\&M ve Zara markalarının başarısıyla; hızlı modanın çevre üzerinde yarattığı tahribatta ölçülebilir bir azalma olacağı öngörülmektedir. Bu markalar, aynı zamanda inovatif sürdürülebilir ürün araştırmalarına verdikleri desteklerle, üretim ve yönetimde şeffaflık ve etik anlayışı benimsemeleri ile hitap ettikleri geniş kitlelerde sürdürülebilirliğin önemi hakkında farkındalık yaratma misyonu da üstlenmişlerdir. Bu yönleriyle hızlı moda markalarının çevresel, ekonomik ve sosyal yönleri ile değişime öncülük ederek bütüncül biçimde sürdürülebilir modaya doğru evrildiği de aşikardır. Tasarım - üretim-tüketim döngüsündenki "hı" yerini, tasarım- malzeme, üretim sürecikullanma-bakım-onarım-yeniden kullanım-geri dönüşüm-tasarım döngüsüne birakmaktadır. Bu durum gelecek yıllarda moda ve tekstil sektöründe sürdürülebilir kavram ve anlayışların payının arttırılmasına da olanak sağlayabilecektir. Bu başarının gerek sektör içindeki rakip oyunculara gerek diğer sektörlere örnek teşkil edeceği düşünülmektedir. 


\title{
EXTENDED ABSTRACT
}

\section{Sustainability in Textiles: Sustainability Strategies of Fast Fashion Brands}

\author{
* \\ Havva Halaçeli Metlioğlu - Volkan Yakın \\ Çukurova University-Bolu Abant İzzet Baysal University
}

The phenomenon of fashion is one of the main builders of the consumption culture by triggering the desire for change of consumers and affecting their psychological satisfaction more than their physical needs. Contrary to general belief, fashion is related not only with clothing but also it's related with the aesthetic choices of consumers from automobile to home, from food to music. At the same time, fashion is the individual's adaptation to constantly changing aesthetic elements for cultural self-expression and interaction with others. Silhouettes, models, fabrics and patterns that change in clothing fashion are designed and marketed with a new story in clothing fashion. The term fast fashion, on the other hand, is a term used by clothing retailers since the 1980s and while it accelerates the transition of a clothing product from fashion shows to showcases, it not only increases consumption but also shortens the life of a product. The fast fashion phenomenon shortens the design-production-sales cycle, and the limited time of access to the product reflects to the consumer as an instinctive buying behavior. With these aspects, fast fashion has increased the amount of waste textile in the world up to 5 times. The concept of sustainability has taken its place on the international stage since the 1990s with the coming to the fore of echological concerns and returning to nature trends in textile production since the 1970s. The basis of sustainability defined as an environmental, social and economic development modellies in the correct and fair use of resources in a way that can be transferred to future generations, the least harm to the environment, the ability of the entire existing human population to reach good living standards and sustain their lives, and to contribute to the economy with innovative products. 
The environmental and economic aspects of sustainability have created green consumers who are highly conscious of environmental problems and whose environmental concerns are reflected in their consumption behavior. It is important for consumers to know that they do not harm the environment while meeting their needs or that the products they consume are relatively less harmful to the environment. Green marketing, on the other hand, brings opportunities to compete as well as social responsibility with the development and marketing of environmentally safe products.

The increase in the impact of global warming on climate change, especially in recent years, has made environmental sustainability an even more important issue and companies working in the textile and fashion field have started to report their measures and steps in this field. It is not expected that fashion and fast fashion, which encourages consumption with its structure that constantly suggests change, will overlap with the concept of sustainability. However, fast fashion brands H\&M and Zara are trying to become environmentally friendly brands with their strategies and advertising campaigns. In particular, sharing the process that a product goes through from the production stage to its access to the consumer provides positive feedback from the consumer. Especially, H\&M actualizes a new and innovative business model that makes sustainability an element of the design process. The use of organic and sustainable fiber, the rental system, the repair of old products and the inclusion of second-hand clothing in the closed loop take part at the outset of H\&M's sustainability strategies. On its website, H\&M has set out its goals to be "fair and equal" to people and the surrounding communities, to be a "circular \& climate" friendly company by using the earth's resources responsibly, and to be the driving force of the fashion industry and a "change leader" in reinvention and transformation. H\&M cooperates with scientists and sustainability institutions in this regard. The circular fashion initiative collaborates with the Ellen McArthur Foundation and is based on the design, materials, manufacturing process, use-maintenance-repair, reuse, recycling, design cycle approach. For this purpose, it has established repair shops where clothes can be repaired and maintained in its department stores in Stockholm, Vienna, London and Paris. In addition, it has included the use of recycled fiber obtained from plastic bottles with its Conscious collection. 
The Science Stoy collection includes Desserto ${ }^{\circledR}$, a vegan leather made from the cactus plant, which was produced as a result of a collaboration between scientists developing cutting-edge materials and requires very little water to grow. Beside this vegan grape skin Vegea ${ }^{\mathrm{TM}}$, silk-like Orange Fiber from citrus peels, and Agraloop ${ }^{\mathrm{TM}}$ BioFibre $^{\mathrm{TM}}$, a natural fiber made from crop waste are also used in its collections.

H\&M has promissed to use sustainable and recycled fiber in all of its products by 2030. Zara announced to the public that all its products by 2025 promised to be sustainable, that they will include containers for collecting old products in their stores and that they will put an end to disposable bags by 2023.

Zara's sustainability strategies can be grouped under the headings of +care for fiber, +care for water and +care for planet by approving the "join life" standard attached to the Higg index. +Care for fiber describes production from sustainable base materials such as recycled polyester yarns, recycled wool and cotton, TENCEL $®$ lyocell or all organic cotton. In the +Care for planet head, there are clothes produced with the use of technologies such as renewable energy, which allow to reduce emissions and the use of chemicals in the product. In addition, Zara's sustainability strategies include the new plastic economy determined by the Ellen Mac Arthur Foundation, the use of recycled fiber and organic cotton, the use of fabric waste cut with the principle of circularity in new clothes, and the savings in water and energy consumption. Zara has declared $80 \%$ renewable energy consumption in 2025 , using $100 \%$ more sustainable cotton, linen and $100 \%$ recycled polyester.

Zara promotes the use of raw materials that support biodiversity conservation, not only in the clothing production chain, but also in the packaging of products and in store furniture.

When examined from all these aspects, the strategies of H\&M and Zara within the scope of sustainability not only make them environmentally friendly brands, but also force other apparel companies to take realistic steps in sustainability. 


\section{Kaynakça / References}

Anderson, J.(2019). Timeless classics made from recycled PET bottles. 4.12.2019 tarihinde https://www2.hm.com/en asia1/life/culture/inside-h-m/h-m-autumn-conscious-collection-2019.html adresinden erişilmiştir.

Atalayman, N. (2019). Gelişen teknoloji ve moda eğilimlerinin günümüz denim modasına etkileri.(Yayınlanmamış Yüksek Lisans Tezi). Dokuz Eylül Üniversitesi , Güzel Sanatlar Enstitüsü, İzmir

Aytekin P. ve Çelik B. (2017). Environmentalist approach and attitudes towards green advertising. International Journal of Business Management E Economic Research, 8(6), 1099-1108.

Baskaran, V., Nachiappan, S., and Rahman, S. (2012). Indian textile suppliers' sustainability evaluation using the grey approach. International Journal of Production Economics, 135(2), 647-658.

bbc.com, (2019). Giyim markası Zara 2025 yılına kadar tüm kıyafetlerin 'sürdürülebilir olacağ1' sözünü verdi. 5.01.2020 tarihinde https://www.bbc.com/turkce/haberler-dunya-49026665, $\quad 4.12 .2019$ adresinden erişilmiştir.

Bellenger, D. D. Robertson, D. ve Hirschman, E. (1978). Impulse buying varies by product. Journal of Advertising Research, 18(6), 15-18

Bianchi, C. and Birtwistle, G. (2012) Consumer clothing disposal behaviour: A comparative study. International Journal of Consumer Studies, 36(3), 335-341.

Can,Ö. ve Ayvaz, K.M. (2017). Tekstil ve modada sürdürülebilirlik. Akademia Sosyal Bilimler Dergisi, 1(3), 110-119.

Clarke, T. ve Clegg, S. (2000). Changing Paradigms, Longman, Sydney.

Colombo, U. (2001). The Club of Rome and sustainable development. Futures, 33(1), 7-11.

Definitions of Marketing (2017), https://www.ama.org/the-definition-of-marketing-what-is-marketing/

Ewa.danışmanlık.com.tr. Gıda ve İçecek Sektöründe Sürdürülebilir Değer ve Kalite Yaratmak, 05.01.2019 tarihinde https://www.ewadanismanlik.com.tr/tr/kaynak/ewa-yayinlari/surdurulebilirligi-anlamak/gidave-icecek-sektorunde-surdurulebilir-deger-ve-kalite-yaratmak adresinden erişilmiştir.

Gardetti, M. A. and Torres, A. L. (2017). Sustainability in fashion and textiles: values, design, production and consumption. Routledge. 
Goworek, H., Cooper,T., Woodward, S. and Hiller, A.(2012). The sustainable clothing market:An evaluation of potential trategies for UK retailers. International Journal of Retail and Distrubition Management,40(12), 935955.

Haciola, Y. ve Atilgan, T. (2014). Research on fast fashion and fast fashion retailing in Turkish apparel sector. Tekstil ve Konfeksiyon, 24(2), 143150.

Handfield, R.B. and Melnyk, S.A. (1996). GreenSpeak. PurchasingToday (July), 32-36.

Heinberg, R., \& Lerch, D. (2010). What is sustainability. The post carbon reader, 11-19.

H\&M Group Sustainability Report. 2017. 5.12.2018 tarihinde https://about.hm.com/content/dam/hmgroup/groupsite/documents/masterlanguage/CSR/reports/2017\%20Sustainability\%20report/HM group SustainabilityReport 2017 FullReport.pdf adresinden erişilmiştir.

Iran, S., Schrader, U. (2017). Collaborative fashion consumption and its environmental effects. Journal of Fashion Marketing and Management: An International Journal, 21(4), 468-482.

Joy, A., Sherry, J. F., Venkatesh, J. A., Wang, J. and Chan, R. (2012). FastFashion, sustainability, and the Ethicalappeal of LuxuryBrands. Fashion Theory, 16(3), $273-296$.

Kaiser, Susan.B., (1997). The Social Psychology of clothing: Symbolic appearances in context. USA:Fairchild Pub.

Kunzing R. (2020). Çöpün sonu. National Geographic,3, 46-69

Madran C. ve Yakın V. (2018). Sürdürülebilirlik ve paylaşım ekonomisi, Ed. Ay C.Yakın V., Kacar. A.I., Paylaşım Ekonomisi 'A'dan Z'ye Tüm Boyutlarıla' Ankara: Akademisyen Yayınevi.

Makeitlast.se. (2017). H\&M launches a 'Closed Loop' denim collection. 04.12. 2019 tarihinde http://makeitlast.se/2017/09/26/hm-launches-a-closedloop-denim-collection/ adresinden erişlimiş̧ir.

Mangır, A . (2016). Sürdürülebilir kalkınma için yavaş ve hızlı moda . Selçuk Üniversitesi Sosyal Bilimler Meslek Yüksekokulu Dergisi , cilt 19,143-154

McDonough, W. and Braungart, M. (2010). Cradle to cradle: Remaking the way we make things. North point press.

Melnyk, S. and Handfield, R. (1996). Greenspeak. Purchasing today, July, 32-36. 
Moisander, J. (2007). Motivational complexity of green consumerism. International journal of consumer studies, 31(4), 404-409.

Nielsen. (2015). The sustainability imperative new insights on consumer expectations. 05.07.2019 tarihinde https://www.nielsen.com/ssa/en/insights/report/2015/the-sustainability-imperative-2/ adresinden erişilmiştir.

Piron, F. (1991). Defining impulse purchasing. Advances in Consumer Research, 1(18), 509-514.

Saka H., (2018). Moda dünyaya pahalıya patlıyor. https://www.yenisafak.com/hayat/moda-dunyaya-pahaliya-patliyor-3246448

Scoones, I. (2007). Sustainability. Development in practice, 17(4-5), 589-596.

Sproles, G. B. (1981). Analyzing fashion life cycles: principles and perspectives. The Journal of Marketing, 45(4), 116-124.

Steiner, M. and Wiegel, U. (2009). Katı atık yönetimi. Ankara: Eflatun.

Şanlı, L.(2018). Dokuma tasarımında atık plastik poşetlerin doku olanaklarının araştırılması. (Yayımlanmamış Yüksek Lisans Tezi). Çukurova Üniversitesi, Sosyal Bilimler Enstitüsü, Adana.

The Higg Index 27.03.2021 tarihinde https://apparelcoalition.org/the-higg-in-

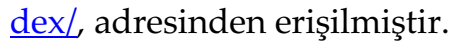

Todeschini, B.V., Cortimiglia, M. N., Callegaro-de-Menezes, D. and Ghezzi, A. (2017). Innovative and sustainable business models in the fashion industry: Entrepreneurial drivers, opportunities, and challenges. Business Horizons, 60, 759-770.

Tüfekçi, İ., Erciş, A. ve Türk, B. (2014). Moda odaklı içgüdüsel satın alma davranışına etki eden faktörler. Dokuz Eylul University Journal Of Graduate School Of Social Sciences, 16(4),587-606.

Walker, S. (2006). Sustainable by design: Explorations in theory and practice. London:Earthscan.

Wigley, S. M., Sinha, P., Goworek, H., Fisher, T., Cooper, T., Woodward, S. and Hiller, A. (2012). The sustainable clothing market: An evaluation of potential strategies for UK retailers. International journal of retail $\mathcal{E}$ distribution management, 40 (12).

Verplanken, B. ve Herabadi, A., (2001). Individual Differences in Impulse Buying Tendency: Feeling and No Thinking. European Journal of Personality, 15, 71-83 
Yakın V., Dursun T., (2018). Değişen dünya ve tüketici davranışları. Ed. Güven E., Çavuşoğlu S., Yeni Nesil İşletmelerde Güncel Ĕ̆gilimler. İstanbul: Beta Yayınevi.

Yanmaz, K. (2014). Kadın giyiminde eski kıyafetlerin geri kazanımı. (Yayımlanmamış Yüksek Lisans Tezi). Güzel Sanatlar Ensitütüsü, Tekstil ve Moda Tasarim Anasanat Dalı, Dokuz Eylül Üniversitesi, İzmir.

WCED (World Commission on Environment and Development. (1987). Our Common Future, OxfordUniversity Press, Oxford.

Zara.com. Ürünler. 26.03.2021 tarihinde www.zara.com/tr/tr/surdurulebilirlik-urunler-11455.html adresinden erişildi.

\section{Kaynakça Bilgisi / Citation Information}

Halaçeli Mertoğlu, H. ve Yakın, V. (2021). Tekstilde sürdürülebilirlik: Hızlı moda markalarının sürdürülebilirlik stratejileri. OPUSUluslararası Toplum Araştırmaları Dergisi, 18(Yönetim ve Organizasyon Özel Say1s1), 1883-1908. DOI: 10.26466/opus.873787. 